\title{
Correction to: A new uncertain DEA model and application to scientific research personnel
}

\author{
Meilin Wen ${ }^{1,2} \cdot$ Xue $\mathrm{Yu}^{1,2} \cdot$ Fei Wang $^{3}$ (D)
}

Published online: 11 December 2019

(C) Springer-Verlag GmbH Germany, part of Springer Nature 2019

\section{Correction to: Soft Computing}

https://doi.org/10.1007/s00500-019-04555-6

The article "A new uncertain DEA model and application to scientific research personnel", written by Meilin Wen, Xue Yu and Fei Wang, was originally published electronically on the publisher's Internet portal (currently SpringerLink) on 26 November 2019 with open access. With the author(s)' decision to step back from Open Choice, the

copyright of the article changed on 12 December 2019 to (C) Springer-Verlag GmbH Germany, part of Springer Nature 2019, and the article is forthwith distributed under the terms of copyright.

The original article has been corrected.

Publisher's Note Springer Nature remains neutral with regard to jurisdictional claims in published maps and institutional affiliations.

The original article can be found online at https:// doi.org/10.1007/s00500-019-04555-6.

Fei Wang

wangfei@buaa.edu.cn

1 Science and Technology on Reliability and Environmental Engineering Laboratory, Beijing, China

2 School of Reliability and Systems Engineering, Beihang University, Beijing, China

3 Research Institute of Frontier Science, Beihang University, Beijing 100191, China 